\title{
Habermas y Marcuse contra la ideología tecnocrática. Divergencias en la Teoría Crítica
}

\author{
Habermas and Marcuse against Technocratic Ideology. \\ Divergences in the Critical Theory
}

Resumen: el presente trabajo pretende aportar, partiendo de la discusión en torno al papel ideológico que cumplen las fuerzas productivas en las sociedades industriales avanzadas, un rastreo genealógico de algunos de los conceptos fundamentales de la propuesta teórica de Jürgen Habermas**. El análisis partirá de la original propuesta normativa, en términos de una formación discursiva de la voluntad política, con que Habermas trata de superar la conciencia tecnocrática, distanciándose de este modo de la primera Teoría Crítica, y más específicamente de Marcuse.

Palabras clave: Habermas, Marcuse, fuerzas productivas, ideología, técnica.

\begin{abstract}
: the aim of this paper is to offer, based on the discussion about the ideological function of productive forces in advanced industrial societies, a genealogical research of some of the basic concepts of Jürgen Habermas's theory. The research shall include the original normative proposal, in terms of discursive formation of a common political will, with which Habermas tries to overcome the technocratic consciousness. Doing that, Habermas distances himself from the first generation of Critical Theory, specifically from Marcuse.
\end{abstract}

Keywords: Habermas, Marcuse, productive forces, ideology, technology.

\section{Introducción}

Uno de los rasgos más particulares del pensamiento de Jürgen Habermas es esa ininterrumpida tendencia a formular sus propias tesis en el contexto de discusiones con teorías que le preceden. A este ejercicio parecen subyacer dos intenciones: la de introducir el aguijón crítico en la propuesta teórica de la que se parte, mostrando su insuficiencia para dar cuenta

Fecha de recepción: 24/07/2015. Fecha de aceptación: 14/03/2016.

* Personal Investigador en Formación en la Facultad de Filosofía y Ciencias de la Educación de la Universidad de Valencia. Correo electrónico: cesar.ortega@uv.es Líneas de investigación: teoría crítica de la sociedad, ética del discurso, teoría moral, filosofía política. Publicaciones recientes: “Naturalizar la idea de justicia? Una respuesta crítica desde la teoría moral de Jürgen Habermas”. Pensamiento, 72 (273), 2016, 827-848. “¿Naturalismo blando? En torno al estatuto epistemológico de la teoría moral de Jürgen Habermas", Anuario Filosófico (Aceptado. Pendiente de publicación).

** Este estudio se inserta en el Proyecto de Investigación Científica y Desarrollo Tecnológico FFI201347136-C2-1-P, financiado por el Ministerio de Economía y Competitividad, y en las actividades del grupo de investigación de excelencia PROMETEO/2009/085 de la Generalitat Valenciana. 
de un determinado estado de cosas; y la de fundamentar en tal insuficiencia la necesidad de una nueva aportación conceptual, que viene a complementar lo que de correcto había en la teoría criticada.

La discusión con Niklas Luhmann y su posterior apropiación de conceptos de la teoría de sistemas (Habermas, 2000, 309-419); la controversia con Gadamer y su asimilación de los conceptos hermenéutico-filosóficos (Habermas, 2000, 218-275); o la discusión con Hannah Arendt, de la que Habermas extrajo un poderoso instrumental conceptual en torno a las ideas de comunicación y poder (Habermas, 2000 a, 205-226), constituyen solamente algunos de los ejemplos más significativos. Por lo demás, esta "apropiación crítica de lo heredado" se muestra de una forma particularmente nítida en la estimulante discusión que entre los años sesenta y setenta del pasado siglo Habermas mantuvo con la tradición marxista (Habermas, 1989; 1992; 2000; 2000a; 2002; 2009).

En lo que sigue nos proponemos abordar un tema muy específico de esta discusión, a saber, la disputa mantenida en el seno de la Teoría Crítica en torno a la ideologización de que son objeto la ciencia y la técnica, y por tanto las fuerzas productivas -en tanto aquéllas representan hoy "el verdadero motor del despliegue" de éstas (Habermas, 1992, 49)-, en las sociedades del capitalismo tardío o capitalismo posliberal organizado. El núcleo del debate consistía en discernir hasta qué punto las fuerzas productivas seguían representando en la nueva sociedad el potencial emancipador que Marx les había reservado en las sociedades del capitalismo liberal.

Nuestra intención pasa por reconstruir cuidadosamente esta disputa, de suerte que termine por mostrarse como un ejemplo del típicamente habermasiano ejercicio de "apropiación crítica" de la tradición filosófica. Entender este ejercicio permanentemente discursivo como algo característico del pensamiento de Habermas puede ofrecer un adecuado punto de vista desde el que leer la hoy ya consolidada propuesta teórica del autor. Sólo si se logra comprender la teoría discursiva de Habermas como el resultado de una formación evolutiva que arranca con los debates dentro de la Teoría Crítica, tal es nuestra tesis, puede garantizarse una correcta aproximación a las discusiones que surgen hoy dentro de la propia teoría de Habermas.

Dado que un tal análisis no puede emprenderse de forma general, vamos a limitarnos a uno de los lugares en que esta problemática queda expuesta más nítidamente, a saber, la discusión entre Habermas y Marcuse acontecida durante los años sesenta. Por otra parte, el presente trabajo tampoco pretende leer dicha disputa bajo la óptica de la ahora mucho más refinada teoría habermasiana. Esta tarea ha sido ya realizada con creces tanto desde dentro de nuestras fronteras (Cortina, 2008; Ureña, 2008; Gabal, 1980; Boladeras, 1996) como desde fuera (McCarthy, 1987; Wellmer, 1990; 1979). Nuestra intención es más bien la inversa: mostrar cómo el análisis de una determinada discusión mantenida por Habermas hace ahora casi medio siglo consigue alumbrar un momento germinal de su posterior aparato teórico, toda vez que el esquema fundamental que se esbozara en aquellos años por vez primera, es decir, el "esquema de las dos dimensiones" (Ureña, 2008, 115) -la dimensión técnica o trabajo y la dimensión comunicativa o interacción en el proceso de autoconstitución de la especie-, no ha sido ya abandonado desde entonces. La ética discursiva, la política deliberativa y, en fin, la teoría de la acción comunicativa en que ambas se sustentan, no pueden comprenderse hoy sin atender a la vez a las antiguas discusiones que, por así decir, constituyen su raíz. 
Para cumplir con este objetivo se tratará de localizar, en primer lugar, la denuncia de Habermas contra la conceptualización marxiana de las fuerzas productivas, denuncia que puede entenderse como una continuación de la crítica de la razón instrumental emprendida por la primera generación de la Escuela de Frankfurt -Adorno, Horkheimer y Marcuse. En segundo lugar se expondrá la teoría del capitalismo tardío y su renovado fundamento ideológico realizada por Herbert Marcuse en los años sesenta. Se estudiará tras ello el momento exacto en que Habermas, discutiendo con Marcuse, avanza desde la postura tradicional de la Teoría Crítica hasta un nuevo punto de apoyo desde el que emitirá su posterior teoría. A fin de corroborar nuestra tesis, trataremos de leer en cuarto y último lugar algunos conceptos fundamentales de la teoría moral habermasiana a la luz de la problemática dibujada en los puntos anteriores.

\section{La crítica habermasiana al reduccionismo de Marx}

Una de las claves de la ruptura de la Escuela de Frankfurt con respecto a la ortodoxia marxista fue el cuestionamiento, en vistas de los hechos acontecidos hacia el final de la República de Weimar -estalinización del socialismo soviético, ascenso del fascismo en Alemania, etc.-, del papel que las fuerzas productivas habrían de ocupar en el proceso de emancipación. Si en gran parte de la sistemática marxiana las fuerzas productivas se consideraban factores inmediatamente emancipadores, los textos del Institut für Sozialforschung a partir de los años treinta (Marcuse, 1968, 1985; Horkheimer, 2010, 2008; Adorno, 1975) muestran en qué sentido dichas fuerzas, encabezadas por la tecno-ciencia, habían perdido su "candidez ideológica" (Habermas, 1992, 49).

Se ha solido definir este tránsito (Cortina, 2008, 55-70; Dubiel, 2000: 79-89; Ureña, 2008: 21-31; Wellmer, 1979: 137-157) como un paso desde la crítica de la economía política marxista, donde el objeto de la crítica ideológica continuaba siendo la falsa conciencia burguesa de "la justicia inherente al intercambio de equivalentes" (Habermas, 1975, 39), hasta una crítica de la razón instrumental, encaminada a mostrar el reduccionismo con que el positivismo y la tecnocracia alcanzaban a eliminar todo resquicio de racionalidad en las cuestiones prácticas, encumbrando así ese tipo de razón que Horkheimer había llamado "instrumental", Marcuse "unidimensional", Adorno "identificante" y Habermas "técnicoestratégica". El triunfo del positivismo, que Marcuse define como una suerte de "sadomasoquismo académico, autohumillación y autodenuncia intelectual” (Marcuse, 1985: 200), y en definitiva como la forma más avanzada de ideología, implica una derrota de la que los frankfurtianos consideraban "auténtica filosofía" (Horkheimer, 2010: 163). Este "culto a los hechos" implica que la filosofía "pierde su talante caudal crítico, ya que la razón se reduce a un mecanismo para adaptarse a lo que hay" (Conill, 1991: 101).

La culminación de este tránsito hacia la crítica de la razón instrumental ha sido filosóficamente representada por la Dialéctica de la Ilustración (Adorno y Horkheimer, 2003). A su vez, tal dialéctica ha encontrado su histórica culminación en la "barbarie de la aniquilación industrial de los hombres a mediados del siglo XX” (Dubiel, 2000: 81).

Aunque resultaría cómodo ubicar dentro de esta misma deriva todos los textos producidos por la primera generación de la Escuela a partir de 1941, y en cierto modo el común denominador de la crítica contra el positivismo y la asunción de una filosofía negativa de la 
historia otorgan cierta legitimidad a dicho gesto, ocurre que el pensamiento de uno de estos autores, Herbert Marcuse, supone un cierto cambio de paradigma en la Teoría Crítica. Dicho de una manera evidentemente simplista, pareciera como si Marcuse no se conformara con la postulación de una opresión sistémica total, sino que considerara necesaria la introducción de una teoría sobre las "alternativas reales" al dominio descrito, ya fuera en la forma de una técnica no represiva (Marcuse, 1985), ya en la de una teoría de los impulsos, de tintes freudomarxistas, encaminada a mostrar la existencia de una "represión sobrante" (Marcuse, 1968).

Acaso sea por esto que Habermas, al menos tan interesado como Marcuse en escapar a la encrucijada de la Dialektik der Aufklärung, eligió un fragmento de El hombre unidimensional para, discutiendo al mismo tiempo que asumiendo las tesis allí aparecidas, avanzar en su particular y quizás más refinada propuesta normativa para la eliminación de la falsa conciencia. Naturalmente que esta eliminación -la crítica de las ideologías- es un elemento capital para comprender la totalidad de la propuesta habermasiana, y en tal sentido nuestras afirmaciones de la introducción. Pero antes de abordar esta discusión es preciso definir todavía la tradicional crítica frankfurtiana al objetivismo de la ortodoxia histórico materialista desde las categorías de Habermas.

Desde sus textos más tempranos, especialmente Teoría y Praxis, Ciencia y Técnica como ideología, La reconstrucción del materialismo histórico y Conocimiento e Interés, Habermas ha mostrado, inserto en el paradigma de la crítica al positivismo, que existe en el interior del pensamiento de Marx una suerte de tensión irresuelta fundamental, desde luego no exenta de consecuencias tanto para la teoría del conocimiento que en dicho pensamiento subyace, como para la posterior apropiación política de su teoría (Wellmer, 1990: 16-18). Habermas muestra cómo la crítica de la economía política, y la teoría históricomaterialista a ella asociada, requieren para sí un concepto de praxis que no se corresponde con los supuestos antropológicos y epistemológicos del pensamiento del propio Marx. Tales supuestos, aparecidos en los Manuscritos (Marx, 1984), habían reducido la praxis a la dimensión del trabajo, es decir, al despliegue de las fuerzas productivas. Expliquemos esto más detenidamente.

Marx había localizado el mecanismo del progreso, es decir, "la superación de una forma de vida petrificada en positividad" (Habermas, 1989, 56), en el despliegue de las fuerzas productivas. Sin embargo, su propia teoría histórico-materialista advertía de que la cientifización de la producción era por sí misma incapaz de garantizar un progreso emancipatorio: la teoría de Marx reconocía que la autoproducción del hombre no se agotaba en el progreso científicotécnico -ámbito del trabajo-, sino que exigía además una modificación de las relaciones de producción, es decir, de las "relaciones de poder que fijan las interacciones de los hombres entre sî" (Habermas, 1989, 60). En este punto Marx cuenta ya con un concepto de interacción no reducido a la actividad productiva; es decir, distingue claramente entre acción instrumental y acción comunicativa. Mientras la sociedad debe emanciparse del "sometimiento exterior a la naturaleza" mediante la intensificación científico-técnica de la acción instrumental en los procesos de trabajo, la emancipación de la "coerción de la naturaleza interna" -represión socialdebe realizarse mediante una sustitución de las instituciones dominantes por una "organización de la interacción social que sólo esté vinculada a una comunicación libre de toda dominación" (Habermas, 1989, 62). Esto último no puede derivarse simplemente de la actividad productiva, sino que exige un concepto de praxis no reducido en términos objetivistas. 
Por otra parte, Habermas muestra cómo los supuestos antropológicos marxianos incurren precisamente en esta reducción objetivista del concepto de praxis. A juicio de Habermas, Marx termina por equiparar su teoría de la sociedad con una ciencia de la naturaleza, de suerte que el proceso práctico-emancipador se realiza bajo la forma tecnocrática de un control instrumental de las relaciones de producción (Habermas, 1989, 56). Este reduccionismo queda finamente expresado por Habermas cuando afirma que la revolución misma se convierte en una fuerza productiva. Según Albrecht Wellmer, esta tendencia terminó por orillar, a través de la relectura de Engels, en una recepción determinista del marxismo. Dicha recepción olvidó el aspecto práctico-comunicativo -el aspecto genuinamente críticoque sin embargo constituía una pieza clave en la crítica de la economía política marxiana (Wellmer, 1990, 20).

Es justamente contra este reduccionismo contra el que Habermas reacciona. A su juicio, "Marx no explica la conexión entre trabajo e interacción, sino que bajo el rótulo inespecífico de práctica social reduce lo uno a lo otro, es decir, la acción comunicativa a la instrumental" (Habermas, 2009, 49). En el seno de su reconstrucción del materialismo histórico, Habermas responderá a esta carencia afirmando que los acontecimientos "evolutivamente trascendentes" (Habermas, 1992, 11) no sólo se dan en las fuerzas productivas -trabajo-, sino también en los procesos de interacción. Este concepto de "racionalización doble", donde el acento recae en la re-colonización de la acción comunicativa bajo el imperativo del consenso, constituye uno de los núcleos de la posterior teoría de Habermas. Adela Cortina ilustra este giro refiriendo un cambio "desde la utopía del trabajo a la utopía de la comunicación" (Cortina, 2008, 113).

Enunciada la crítica habermasiana, formulemos ahora la muy aguda apreciación de Marcuse, que Habermas hereda, sobre la ideología tecnocrática.

\section{Herbert Marcuse ante la ideología tecnocrática}

Una breve enumeración de las distintas fases que atravesó el pensamiento de Herbert Marcuse ayudará a ubicar el momento en que se emiten las tesis de la disputa que nos interesa. Dicho sucintamente, podemos diferenciar tres grandes etapas en la filosofía de Marcuse: una primera marcada por las categorías de Heidegger, de quien fue discípulo (Marcuse, 2010; 2011); una segunda, donde el joven Marcuse se convierte en un activo colaborador del círculo reunido por Max Horkheimer en Nueva York hacia los años treinta (Marcuse, 1968a, 1971b); y una tercera, que, permaneciendo dentro de la nueva orientación que había asumido la Teoría Crítica -es decir, en el marco de la crítica de la razón instrumental, que en esos años culminaba con la publicación de Dialektik der Aufklärung y Eclipse of Reason-, pretendía sin embargo un doble gesto: continuar la crítica a la "totalización de la razón instrumental", y proponer alternativas reales a dicha totalización (Marcuse, 1968; 1985; 1971).

Esta última fase, donde la Teoría Crítica ya había abandonado su esperanza en la función inmediatamente emancipadora de las fuerzas productivas, da cuenta de aquella apreciación que hacíamos en el capítulo precedente. En efecto, el pensamiento de Marcuse, a diferencia del, por decirlo groseramente, pesimismo de Horkheimer y Adorno, no se limita a "circunscribir lo inexpresable" (Habermas, 2000a, 284) de un dominio sistémico postulado como insuperable, sino que persigue una formulación específica de alternativas futuras. Por cierto 
que este difícil juego de equilibrismo entre la tesis de la unidimensionalidad de la conciencia y la postulación de alternativas posibles surgidas desde dentro de dicha unidimensionalidad ha sido objeto de críticas difícilmente soslayables (Offe, 1969, 72-86; Habermas, 2002, 326).

Este cariz a la vez crítico y esperanzador se observa en textos como Eros y Civilización -donde una relectura de la teoría freudiana de las pulsiones expone la posibilidad de una sustitución del principio de realidad por un renovado principio del placer, de suerte que "el trabajo socialmente útil [llegue a ser] a la vez la transparente satisfacción de una necesidad individual" (Marcuse, 1968, 195)-; "Industrialización y capitalismo en la obra de Max Weber" - donde Marcuse desmonta la lectura weberiana de la racionalidad del capitalismo, según la cual la razón formal se encuentra en sí misma conectada con el dominio (Marcuse, 1971, 130-140) -; o El hombre unidimensional -donde Marcuse expone su crítica al papel ideológico de las fuerzas productivas en las nuevas sociedades. Es preciso analizar las tesis defendidas en este último libro con algo más de detenimiento, puesto que en ellas queda representado claramente el núcleo de nuestra discusión.

A nuestro modo de ver, la obra puede ser leída desde dos tesis fundamentales. La primera de ellas, enunciada ya al comienzo del prefacio, pone de manifiesto la forma de instauración de un dominio racionalizado en las sociedades industriales avanzadas, dominio que encuentra su base legitimadora, y por tanto la ocasión para perpetuarse, en la oferta de un nivel de vida creciente de acuerdo con los progresos de la tecno-ciencia-como motor primero del sistema productivo. La segunda formula la posibilidad de cancelar esa inmunización que el sistema capitalista hace de sí mismo; es decir, enuncia, mediante una crítica ideológica, la posibilidad de la transformación social. Adherida a esta segunda tesis se halla el presupuesto fundamental de la obra, sin el cual no puede comprenderse la formulación de alternativas históricas: la sociedad industrial avanzada, y la estructura científico-técnica en que se basa, es un proyecto histórico concreto.

En la primera tesis, Marcuse muestra cómo la creciente satisfacción de necesidades garantizada por la organización técnica de la sociedad tiene como correlato la exigencia de una aceptación ciega del principio de realidad en que aquélla se asienta -es decir, "la suma total de normas y valores que dominan en una sociedad" (Marcuse, 1976, 5). Este principio es bautizado en Eros y Civilización como "principio de actuación", y definido como la estratificación de la sociedad "de acuerdo con la actuación económica competitiva de sus miembros" (Marcuse, 1968, 54). Dadas las condiciones de un nivel de vida creciente, dice Marcuse, la disconformidad con el sistema que garantiza tal crecimiento aparece como una actividad socialmente inútil: la satisfacción material impide que el sujeto encuentre razones para interesarse por una autónoma autodeterminación, y esto se convierte en la "base racional y material para [...] la conducta unidimensional" (Marcuse, 1985, 81).

La imposición por parte del sistema de unas necesidades en realidad heterónomas consigue a la vez una interiorización individual de las mismas y una perpetuación de la represión que su aceptación implica: cultura de la competencia, de la lucha por la existencia, de la miseria, de la injusticia. La forzada identificación de los individuos con aquellas necesidades que eternizan el propio sistema implica una hasta ahora inédita relación del sujeto consigo mismo: el sujeto "ha llegado al extremo de estar alienado de su propia alienación" (Ureña, 2008, 58). ¿Cuál es en este sentido el objetivo de una teoría crítica de la sociedad? Naturalmente, el despertar de la conciencia adormecida, la crítica ideológica: "la sustitución de las 
necesidades falsas por otras verdaderas, el abandono de la satisfacción represiva" (Marcuse, 1985, 37).

Es importante observar el giro que opera aquí el concepto clásico de ideología. En las sociedades industriales avanzadas "el sujeto alienado es devorado por su existencia alienada. Hay una sola dimensión que está por todas partes. Los logros del progreso desafían tanto la denuncia como la justificación ideológica; ante su tribunal, la "falsa conciencia" se convierte en verdadera conciencia. [...] La ideología se encuentra hoy en el propio proceso de producción" (Marcuse, 1985, 41). La alienación "pierde su forma, económicamente evidente, de miseria" (Habermas, 2002, 216), de suerte que "el manipulado consumo de cultura confirma tan sólo de una nueva forma, ciertamente más agradable, una antigua relación de poder" (Habermas, 2002, 223).

Por otra parte, Marcuse formula su presupuesto fundamental con las siguientes dos afirmaciones: primero, que "el a priori tecnológico es un a priori político" (Marcuse, 1985, 181); segundo, que dicho a priori responde a un proyecto histórico determinado, es decir, es fruto de una "decisión". La primera tesis significa que la ciencia y la técnica aportan los instrumentos para la "dominación del hombre por el hombre a través de la dominación de la naturaleza" (Marcuse, 1985, 186). ¿Cómo acontece este dominio? "La naturaleza, comprendida y dominada científicamente, reaparece en el aparato técnico de producción y destrucción que sostiene y mejora la vida de los individuos al mismo tiempo que los subordina a los dueños del aparato. [...] La tecnología se ha convertido en el gran vehículo de la reificación: la reificación en su forma más madura" (Marcuse, 1985, 193-196).

La razón científica, dice Marcuse, permaneciendo pura y neutral, se pone al servicio de la razón práctica política, se hace dominio. En lugar de negar la legitimidad de la dominación, la racionalidad de la ciencia contribuye a proteger esa misma legitimidad: "el horizonte instrumentalista de la razón se abre así a una sociedad racionalmente totalitaria" (Marcuse, 1985, 186). Esta historización del aparato científico técnico, en el sentido de una desnaturalización de dicho proyecto -es decir, en el sentido en que Marx entendió la crítica como desfetichización de la mercancía y las relaciones burguesas (Marx, 1980)- autoriza a Marcuse a proponer alternativas igualmente históricas. Tales alternativas exigen subvertir los fines específicos que el progreso técnico ha adquirido en esta sociedad, y por tanto pasan por construir una técnica y una ciencia "cualitativamente" diferentes -no al servicio de la revalorización del capital, sino de la pacificación de la existencia en base al desarrollo técnico mismo. Aquí queda ya claramente alumbrada la confrontación con los presupuestos antropológicos de Marx: el despliegue de estas fuerzas productivas, la praxis en términos de trabajo, lejos de ser inmediatamente emancipatorio, constituye la legitimación ideológica del dominio.

Aunque el "proyecto" define el "rango de posibilidades abiertas e impide las posibles alternativas incompatibles con ella" (Marcuse, 1985, 247), la sociedad así establecida "se enfrenta siempre al peligro" de la formulación de proyectos alternativos. Para medir la viabilidad e idoneidad de los nuevos proyectos Marcuse propone dos criterios normativos: la adecuación con las posibilidades reales de la sociedad y la demostración de un grado de racionalidad más elevado que el proyecto establecido, de acuerdo con los criterios de "una mayor oportunidad para la pacificación de la existencia" y un "libre desarrollo de las necesidades y facultades humanas" (Marcuse, 1985, 248). Estos innegociables criterios, esta 
apelación casi idealista a la racionalidad de ciertas relaciones humanas, ha sido defendida por Marcuse desde sus programáticos textos de la Zeitschrift für Sozialforschung. En "Filosofía y Teoría Crítica", Marcuse defiende la existencia de determinadas verdades universales: "que el hombre es un ser racional, que su esencia exige la libertad, que su felicidad es un bien supremo, todas estas son generalidades que, precisamente a causa de su generalidad, encierran una fuerza progresista. La generalidad las dota de una pretensión casi subversiva: no es éste o aquél, sino todos los individuos deben ser racionales, libres, felices" (Marcuse, 1968a, 92). El interés emancipatorio de la Teoría Crítica se fundamenta en la creencia filosófica de que el hombre debe ser algo más que un medio en el proceso productivo (Marcuse, 1968a). En el último punto mostraremos cómo el universalismo moral subyacente a la ética discursiva puede entenderse también a la luz de estas tesis.

Pero si el propio progreso técnico se ha convertido en legitimación del dominio, entonces la crítica debe apuntar a la dirección que ha tomado tal progreso. Esto es lo que Marcuse llama "cambio cualitativo" de la sociedad: el progreso técnico orientado a la pacificación de la existencia, a la consecución de una vida organizada en torno a un "tiempo libre sobre la base de necesidades vitales satisfechas" (Marcuse, 1985, 259). Lejos de querer prescindir del progreso científico-técnico, la propuesta de Marcuse exige la culminación de tal progreso, aunque regido por valores diferentes. Por eso dice Marcuse que "la consumación de la realidad tecnológica" no sólo sería el prerrequisito, sino también "lo racional para trascender la realidad tecnológica" (Marcuse, 1985, 259).

La relectura habermasiana de este pensamiento, que mostrará uno de los tránsitos clave desde la primera hasta la segunda generación de la Escuela de Frankfurt, ejemplificará meridianamente el gesto de apropiación crítica de lo heredado a que nos referíamos en la introducción. Es justamente de este tránsito, tal es nuestra hipótesis, del que no debe prescindirse si quiere abordarse adecuadamente la teoría de Habermas.

\section{Jürgen Habermas: pensar con Marcuse contra Marcuse}

Tal y como hiciéramos con Marcuse, quizás resulte adecuado exponer brevemente las fases fundamentales en que puede dividirse el pensamiento de Jürgen Habermas. Basándonos en el modelo que propone Enrique M. Ureña (Ureña, 2008, 1983-1995), hablaríamos primero de una fase que iría desde la publicación de su primera gran obra en 1962, Historia y crítica de la opinión pública, hasta finales de los años setenta, y en donde la lucha contra el positivismo y las tentativas de construir una teoría crítica de la sociedad ocupan el lugar protagonista. En segundo lugar encontraríamos la fase iniciada con la fundamental Teoría de la Acción Comunicativa, publicada en 1981, y que pasando por textos como Conciencia moral y acción comunicativa, Aclaraciones a la ética del discurso o Facticidad y validez llegaría aproximadamente hasta mediados de los noventa; aquí el acento recaería en los problemas derivados de una "colonización del mundo de la vida", así como en los conceptos de ética discursiva y política deliberativa. Localizaríamos por último una tercera fase, que incluiría textos como El futuro de la naturaleza humana o Entre naturalismo y religión, y en donde Habermas se centraría bien en el interior del mundo de la vida -y en los problemas derivados de sus diversas "doctrinas comprehensivas" (Rawls) o "éticas de máximos" (Cortina)-, bien en la difícil relación de los Estados en el nuevo escenario posnacional. 
La discusión que a nosotros nos ocupa, ubicada evidentemente en la primera fase, encuentra su formulación más específica en Ciencia y Técnica como ideología. Analicemos pues cuidadosamente las tesis allí expuestas en relación con nuestro problema.

En su relectura crítica de Marcuse, Habermas parte de dos tesis fundamentales: en primer lugar, que Marcuse acierta al localizar en la institucionalización del progreso científico técnico el núcleo de la ideología tecnocrática del capitalismo tardío, y por tanto en su crítica al concepto weberiano de "racionalización"; en segundo lugar, que se equivoca al proponer como forma de combatir dicha ideología el modelo de una ciencia y una técnica "cualitativamente diferentes" a las de hecho existentes - que no respalden la legalidad de la opresión de clase, sino que ejerzan un dominio liberador sobre la naturaleza; pues la idea de Marcuse es precisamente la de que "en el a priori material de la ciencia y de la técnica se encierra un proyecto del mundo determinado por intereses de clase y por la situación histórica" (Habermas, 2009, 59).

El ataque habermasiano al supuesto fundamental de la tesis de Marcuse, es decir, al carácter histórico del aspecto dominador de la racionalidad científico técnica, y consecuentemente su ataque a la solución en dicho supuesto fundamentada -la posibilidad de prescindir de tal racionalidad científico técnica en pos de otra cualitativamente diferente-, comienza mostrando qué es exactamente lo que supone su formulación. Naturalmente, no otra cosa que la exigencia de una revolución de la ciencia y la técnica mismas (Habermas, 2009, 59). Tres cosas parecen poder objetarse a esta exigencia: en primer lugar, la cuestionable posibilidad de pensar un "proyecto" histórico alternativo al actualmente establecido -pues sólo bajo la posibilidad de pensar alternativas puede afirmarse la historicidad de la ciencia-; en segundo lugar, el anterior problema se extiende también a la técnica. Como consecuencia de estos dos problemas aparece la tercera objeción. Siguiendo a Arnold Gehlen, Habermas afirma que existe una conexión inmanente entre nuestra técnica y la estructura de la acción racional con respecto a fines. Como es sabido, la pretensión de fundamentar dicha relación entre las distintas ciencias -empírico-analíticas, hermenéuticas y críticas- con tres intereses del conocimiento -técnico, práctico y emancipatorio- es el objetivo del influyente Conocimiento e Interés. Si la evolución de la técnica obedece pues a una lógica de la acción racional con respecto a fines regulada por el éxito -y ésta es la estructura del trabajo, dice Habermas-, entonces no podemos renunciar a nuestra técnica mientras la existencia del ser humano siga dependiendo del trabajo social (Habermas, 2009, 62).

Partiendo de estas objeciones, Habermas relee la problemática de la ideología tardocapitalista desde sus propias categorías. En primer lugar, y con objeto de reformular el concepto weberiano de "racionalización", que había sido a su vez blanco de la incisiva crítica de Marcuse, Habermas propone una distinción entre trabajo e interacción. Por trabajo o acción racional con respecto a fines entiende o bien la acción instrumental -guiada por reglas técnicas-, o bien la elección racional -guiada por estrategias-, o bien una combinación de ambas. $\mathrm{Su}$ validez depende de enunciados empíricamente verdaderos o analíticamente correctos. La acción comunicativa es una interacción simbólicamente mediada, orientada "de acuerdo con normas intersubjetivamente vigentes que definen expectativas recíprocas de comportamiento" reconocidas por al menos dos sujetos. Su validez se funda en la "intersubjetividad del acuerdo sobre intenciones", y queda asegurada por "el reconocimiento general de obligaciones" (Habermas, 2009, 69). Esta categorización, que resulta evidentemente central en 
el pensamiento de Habermas, sólo puede apresarse en toda su complejidad si se dilucida al mismo tiempo el contexto de su aparición, tal y como tratamos de probar.

En función de esta tipología Habermas distingue dos sistemas sociales: el marco institucional del mundo social de la vida, compuesto por normas que dirigen las interacciones simbólicamente mediadas; y el sistema, donde se encuentran los dos subsistemas de acción racional con respecto a fines, a saber, el económico y el estatal.

Mediante ciertos trazos premonitores de su posterior teoría de la evolución social -expuesta algunos años después en Problemas de legitimación en el capitalismo tardío y La reconstrucción del materialismo histórico-, Habermas analiza en función de las categorías señaladas las distintas formas de legitimación política, desde las sociedades tradicionales hasta las sociedades tardo-capitalistas, pasando por la ideología burguesa del capitalismo liberal. A su juicio, las tendencias del capitalismo tardío certeramente localizadas por Marcuse -intervención del Estado en el mercado con el fin de garantizar su estabilidad e institucionalización de la ciencia y la técnica como primeros motores de las fuerzas productivas- hacen imposible que la crítica ideológica siga presentándose bajo los parámetros marxistas. Esta cercanía entre Habermas y Marcuse ha sido definida en el primer punto, exponiendo en qué sentido la crítica habermasiana al reduccionismo marxista quedaba inscrita en la tradicional crítica frankfurtiana a la razón instrumental.

Habermas llega de esta forma a una tematización original de la ideología del capitalismo tardío, a la que denomina "ideología tecnocrática": en las sociedades industriales avanzadas, la formación democrática de la voluntad política en relación con las cuestiones prácticas se sustituye por decisiones técnicas. "La fuerza ideológica de la conciencia tecnocrática queda demostrada precisamente en el encubrimiento que produce de esa diferencia" (Habermas, 2009, 91). La cosificación se lee ahora como colonización del mundo de la vida por parte del sistema (Habermas, 1981); esto es, como "subordinación de ámbitos de la vida cada vez más amplios bajo los imperativos sistémicos" (Gómez Ibáñez, 1995, 105). El diagnóstico marcusiano sobre la conciencia unidimensional se convierte así en una crítica a la conciencia tecnocrática y al privatismo civil.

En un texto dedicado a Arnold Gehlen, y recogido en sus Perfiles filosófico-políticos, Habermas expone, alejándose de la ortodoxia marxista, cómo la emancipación de los individuos humillados exige hoy algo más que la liberación económica de sus vidas. Hoy puede eliminarse la explotación económica y mantenerse aún la falta de libertad, en tanto dicha falta de libertad se sostiene ideológicamente apelando a los valores del privatismo civil -aumento de la capacidad de consumo, reducción de la participación en la vida política pública. En este sentido, el dominio o exclusión de los ciudadanos de una genuina participación democrática, esto es, la opresión política, quedaría legitimado "pretendiendo que la eliminación del hambre significa ya la realización de la libertad y que la superación de la pobreza de las masas significa ya la emancipación de esas masas" (Habermas, 2000a, 109).

Con relación a esto, y frente a la solución esbozada por Marcuse, la propuesta de Habermas pasa por mantener separados dos conceptos diferentes de racionalización, a saber, la racionalización en el nivel de los subsistemas de acción racional con respecto a fines y la racionalización en el nivel del marco institucional. Sólo si la primera no sustituye a la segunda, así rezaría la tesis de Habermas a este respecto, el despliegue de las fuerzas productivas podría actuar como potencial de liberación. Esto significa que el propio proceso 
científico técnico exige una politización de sus fines, politización que ha de depender de una formación discursiva de la voluntad del público de ciudadanos; o dicho de forma más sencilla, de la posibilidad o no que tengan dichos fines para responder a intereses generalizables (Habermas, 2009, 107).

\section{Rastreo genealógico de algunos conceptos fundamentales}

Aunque es claro que la particularidad del pensamiento de Habermas aparece justamente allí donde se distancia de Marcuse -y en general de la primera Teoría Crítica-, no lo es menos que fueron precisamente estas tempranas discusiones las que conformaron los cimientos de la hoy sólida arquitectónica habermasiana. Por eso un rastreo genealógico de los conceptos -como el que acabamos de realizar- resulta de la mayor utilidad a la hora de interpretar, por ejemplo, ciertos contenidos de la teoría moral de Habermas.

En el intento por superar determinadas "aporías hermetizantes" (Maestre, 1989, 235) de la primera Teoría Crítica adquiere sentido el ya célebre "giro lingüístico", del que Habermas es un importante representante, y que en este contexto no significa sino la remisión del fundamento normativo de la crítica a la formación discursiva de la voluntad política. Vamos a analizar este fundamental desplazamiento en relación con algunas ideas rectoras de la ética discursiva, de suerte que ésta pueda ser conceptuada como una evolución crítica de los conceptos cardinales discutidos más arriba.

Si Marcuse había definido la tarea de la crítica como un intento por "sustituir las necesidades falsas por otras verdaderas" (Marcuse, 1985, 37), Habermas se cuestionará sobre el lugar específico desde el cual puede hoy una teoría crítica de la sociedad identificar la verdad de dichas necesidades. Ciertamente que Marcuse apelaba a un determinado fundamento, a saber, la demostración de un grado de racionalidad más elevado que el proyecto establecido de acuerdo con los criterios del libre desarrollo de las facultades y la pacificación de la existencia (Marcuse, 1985, 248). Pero Habermas entiende que sólo mediante la institucionalización de discursos prácticos podrán ser los propios afectados los que, ilustrándose a sí mismos, expliciten el contenido específico de ese "libre desarrollo de necesidades y facultades". Las normas fundamentadas en el discurso práctico, es decir, las normas morales, ofrecen el marco sine qua non para la construcción de ese espacio de libre desarrollo de necesidades. Sólo la fundamentación de una moral universalista, posconvencional, puede recurrir justificadamente a esos ideales de los que el propio Marcuse se había servido, y que desde luego encierran en sí una pretensión progresista -“casi subversiva”, dice Marcuse. Tanto en Habermas como en Marcuse el interés emancipatorio se fundamenta en una creencia filosófico moral, a saber, la de que la existencia humana ha de trascender la condición de medio para devenir fin en sí misma. Por supuesto que Habermas se mueve en el marco de un "pensamiento postmetafísico". Sólo en tanto sujeto capaz de hablar y de actuar, es decir, en tanto sujeto capaz de pronunciarse afirmativa o negativamente ante las pretensiones de validez de los demás, el hombre forma parte de una comunidad moral que es universal

El universalismo moral de la teoría habermasiana encuentra sus fundamentos, por así decirlo, al mismo tiempo en Kant y en Marx. Por ello la reconstrucción detallada de estos debates, igual que la apelación a las discusiones en torno al deontologismo kantiano (Habermas, 2000b, 13-33; 2008, 14-29) o al cognitivismo de la psicología evolutiva (Kohlberg, 
1971; 1992; Habermas, 1992, 67-74; 2000b, 84-105; 2008, 121-175; 2011, 267-272), por nombrar sólo algunas de las fuentes tradicionales, puede ayudar a localizar los lugares germinales desde los que leer hoy la teoría. El entrecruzamiento entre Marx y Kant, por lo demás, se hace de lo más explícito cuando en sus Aclaraciones a la ética del discurso Habermas reivindica la siguiente frase de Horkheimer, aparecida en Materialismus und Moral: "para superar el carácter utópico de la noción kantiana de una Constitución perfecta se necesita la teoría materialista de la sociedad" (Habermas, 2000b, 33).

La disputa sobre los fundamentos normativos de la crítica, que supone un momento especialmente significativo de este rastreo, encuentra un estimulante testimonio en la entrevista mantenida entre Habermas y Marcuse durante el verano de 1977 (Habermas, 2000a, 237-283). Ante los reiterados intentos de Habermas por hacer que su interlocutor responda a la controvertida pregunta de en función de qué criterio puede el teórico crítico definir lo racional, Marcuse recurre una y otra vez al mundo cotidiano de la vida, donde a su juicio pueden encontrarse conceptos con los que formular juicios de valor -libre desarrollo de las facultades, pacificación de la existencia-, y a la teoría freudiana de las pulsiones. Pero la abstracción de tales principios, tal es la objeción de Habermas, hace imposible la tarea de identificar los intereses realmente universalizables -es decir, racionales- de la sociedad. Aunque Marcuse acepta la consigna habermasiana de que sólo los propios afectados pueden determinar la generalizabilidad de los intereses, es Habermas, y no Marcuse, quien hace de este hecho el fundamento normativo de su crítica: lo racional no reside en la vida cotidiana y las pulsiones, sino más bien en la "organización de una formación de la voluntad sin coacciones y general, esto es, en el telos de la intersubjetividad de un acuerdo no distorsionado por la coacción de la fuerza" (Habermas, 2000a, 261). En la teoría crítica de Habermas la "perspectiva del observador", en la que se incluye la figura del propio teórico crítico, queda sustituida por la perspectiva del participante. Desde el punto de vista de esta sustitución, que se ve nítidamente en el debate con Marcuse, adquiere la mayor significatividad el núcleo de la teoría moral habermasiana.

La ética del discurso ofrece, "desde los presupuestos comunicativos universales de la argumentación" (Habermas, 2000b, 127), una reconstrucción racional del kantiano "punto de vista moral". Tan pronto como se entiende este punto de vista moral, que encarna el discurso racional, como el lugar crítico, imparcial, desde el que discutir la universalizabilidad de los intereses de la sociedad "trascendiendo el contexto social e histórico de la forma de vida específica” en que los sujetos habitan (Habermas, 2000b, 132), la teoría de Habermas se convierte en una teoría de la justicia con pretensiones universalistas. Esta teoría responde por lo demás a la misma problemática a que trató de contestar la tradición crítica de la que ella misma surge, a saber, a la posibilidad de una organización racional de la sociedad. La ética discursiva, por así decirlo, localiza el núcleo normativo de la crítica en la moral posconvencional que trata de reconstruir el discurso racional: sólo desde aquí es posible diferenciar "la validez que reclamamos para nuestras concepciones de la mera validez social de una praxis habitual" (Habermas, 2008, 29); o dicho de otra forma, sólo desde aquí pueden diferenciarse las normas fácticamente reconocidas de las normas merecedoras de reconocimiento.

El cambio de acento que opera Habermas con respecto a esta tradición puede rastrearse en algunos de sus textos más tempranos. Ya en Teoría y Praxis el autor avanza una concepción de la crítica manifiestamente separada de la de sus predecesores: "la crítica conceptúa 
el hecho de que su pretensión de validez sólo puede hacerse efectiva en el proceso exitoso de ilustración, y esto significa: en el discurso práctico de los afectados" (Habermas, 2002, 27). Sólo apelando a un consenso racional que parta de un reconocimiento recíproco de pretensiones de validez, pretensiones que deberán problematizarse argumentativamente a fin de comprobar su generalizabilidad, puede todavía hoy, a juicio de Habermas, hablarse de corrección normativa. Como es sabido, Habermas explica este concepto (Richtigkeit) en analogía con el concepto de "verdad" (Wahrheit). Con esta analogía se explicita la fundamental concepción cognitivista de la moral que caracteriza a la ética del discurso: "la capacidad de distinguir juicios verdaderos de juicios tenidos por verdaderos se corresponde claramente con la capacidad de distinguir juicios morales válidos de juicios morales simplemente vigentes de facto" (Habermas, 2011, 268).

El discurso práctico, en tanto eleva al nivel de la reflexividad y de la crítica pretensiones de validez y certezas presupuestas con las que los sujetos se encuentran ya operando en el mundo de la vida, esto es, en tanto convierte toda certeza normativa meramente presupuesta en un enunciado hipotético sobre cuya validez sólo pueden pronunciarse las buenas razones, requiere "la idealización de las condiciones de justificación"; es decir, requiere suponer una "situación ideal de habla" cuya estructura "garantiza la posibilidad de un consenso que hay que alcanzar discursivamente" (Habermas, 2002, 29). A juicio de Habermas, la propia acción de argumentar obliga a los participantes a presuponer contrafácticamente determinadas condiciones, tales como la inclusión, la participación de todos los afectados o la inmunización frente a las coacciones (Habermas, 2011, 249). La ética discursiva consigue así derivar la estructura de una moral universalista "de los presupuestos universales de la argumentación". Evidentemente que la propia "idealización de las condiciones de justificación" entraña importantes problemas teóricos, ante los cuales Habermas y Apel, y también los máximos representantes de la ética discursiva en España (Cortina, 1994; García-Marza y Cortina, 2003), llevan años respondiendo. Pero éste no es ya el tema de este trabajo.

Nuestro propósito es sencillamente tratar de argumentar en qué sentido esta justificación discursiva de determinadas certezas problematizadas puede leerse bajo los parámetros que se han establecido en los capítulos precedentes; es decir, en qué medida puede decirse que esta prueba crítico-argumentativa, que pretende desprenderse de las normas falsamente universalizadas, es heredera de la conocida crítica de las ideologías. Por lo pronto, baste con afirmar, como resultado de la discusión anterior, que la lectura habermasiana de Marcuse oferta unos parámetros normativos desde los cuales superar, de una forma más concreta y desarrollada, la falsa conciencia de una racionalidad instrumental que se basta a sí misma. La tematización de dicha racionalidad se la debe Habermas a los viejos frankfurtianos. Pero si Horkheimer y Adorno agotaron sus esfuerzos en exponer la dialéctica negativa que opera en Occidente, y terminaron por resignarse a un concepto de libertad prácticamente "transformado en una categoría escatológica" (Wellmer, 1990, 29); y si Marcuse pretendió dar un paso más hacia la propuesta de alternativas posibles, pero desde unos fundamentos normativos nebulosamente delimitados, Habermas intenta al mismo tiempo conservar la intención crítica de la vieja tradición de Frankfurt y avanzar hacia una definición rigurosa de los fundamentos normativos desde los que hoy, todavía, puede discutirse sobre la organización racional de la sociedad. 


\section{Conclusión}

Con este trabajo se ha pretendido ofrecer un punto de vista desde el que alumbrar genealógicamente la teoría de Jürgen Habermas. Hemos intentado, con más o menos éxito, demostrar que el debate en torno al papel que cumplen las fuerzas productivas en las sociedades tardo-capitalistas arroja una interesante luz sobre los orígenes del pensamiento de Habermas. Este debate termina por delinear claramente las divergencias entre Marx y la primera Teoría Crítica -que en este artículo ha sido representada por Marcuse-, por una parte, y entre ésta y la teoría de Habermas, por la otra.

En efecto, Marcuse hereda del materialismo de Marx la concepción de que la sociedad racional exige la culminación de las fuerzas productivas, pero entiende, por contra, que dicha culminación no resulta inmediatamente emancipadora en la sociedad industrial avanzada, pues las propias fuerzas productivas han asumido tareas ideológicas. Por su parte, Habermas comparte esta tesis sobre el carácter ideológico del progreso científico-técnico, pero propone una salida diferente a la solución de Marcuse, y desde luego se aleja de la deriva, en términos de una ideologización sin fisuras, que representa la Dialektik der Aufklärung. A su modo de ver, la reorientación de una técnica que hoy cumple funciones ideológicas -o dicho en sus propias palabras: de una "política tecnificada"- en la dirección de una sociedad emancipada exige una racionalización práctica destinada a sustituir las instituciones espontáneamente dominantes por "una organización de la interacción social sólo vinculada a la comunicación libre de todo dominio" (Habermas, 1989, 62).

Esta explicitación del característico gesto habermasiano de la apropiación crítica de lo heredado, pues la nueva lectura surge desde luego de la propia discusión con la tradición marxista, alumbra así un momento germinal de lo que posteriormente será la teoría de la acción comunicativa y las formulaciones adheridas a dicha teoría.

Aunque lo dicho más arriba pretendía una clara diferencia entre las posturas de Habermas y Marcuse con relación al problema de las fuerzas productivas y los fundamentos normativos de la crítica, quisiera terminar señalando la existencia de un punto extremadamente fundamental en el que las dos teorías se tocan. Ambos autores toman como motor de su crítica una experiencia idéntica: es la experiencia del sinsentido; es decir, la experiencia del sufrimiento injustificable de los más desfavorecidos. Uno se ve casi obligado a terminar estas páginas recordando aquellas palabras con que Marcuse, sólo unos días antes de morir, se despidiera de su amigo Habermas, y que éste recuerda en un artículo de 1980 (Habermas, 2000a, 283-296): “¿Ves? Ahora sé en qué se fundan nuestros juicios valorativos más elementales: en la compasión, en nuestro sentimiento por el dolor de los otros".

\section{Bibliografía}

Adorno, T. W. (1975), Dialéctica negativa, Madrid, Taurus [1966].

Adorno, T. W. y Horkheimer, M. (2003), Dialéctica de la Ilustración, Madrid, Trotta [1947]. Boladeras, M. (1996), Comunicación, Ética y Política. Habermas y sus críticos, Madrid, Tecnos.

Conill, J. (1991), El enigma del animal fantástico, Madrid, Tecnos. 
Cortina, A. (1994), «Ética del discurso y bioética», en: D. Blanco Fernández et al. (eds.): Discurso y realidad, en debate con K. O. Apel, Madrid, Trotta, pp. 75-89.

Cortina, A. (2008), La Escuela de Fráncfort. Crítica y utopía, Madrid, Síntesis.

Cortina, A. (2009), «La política deliberativa de Jürgen Habermas: virtualidades y límites», Revista de Estudios Políticos, no 144, 2009, pp. 169-193.

Cortina, A. y García-Marzá, D. (2003), Razón pública y éticas aplicadas: los caminos de la razón práctica en una sociedad pluralista, Madrid, Tecnos.

Cristobo, M. (2013), «Notas sobre el desarrollo del conocimiento "técnico" aplicado en los procesos de trabajo», Intersticios: Revista Sociológica de Pensamiento Crítico, $\mathrm{n}^{\mathrm{o}}$ 7/2, pp. $37-48$.

Dubiel, H. (2000), La Teoría Crítica: Ayer y Hoy, México, Plaza y Valdés.

Feenberg, A. (2009), «Radical philosphy of technology», Radical Philosophy Review, n ${ }^{\circ}$ 12, pp. $199-217$.

Gabal, R. (1980), Jürgen Habermas: dominio técnico y comunidad lingüística, Barcelona, Ariel.

Gómez Ibáñez, V. (1995), «Mundo administrado o colonización del mundo de la vida. La depotenciación de la Teoría Crítica de la sociedad en Habermas», Daimon (Murcia), $\mathrm{n}^{\circ}$ 10, pp. 103-113.

Habermas, J. (1975), Problemas de legitimación en el capitalismo tardío, Buenos Aires, Amorrortu [1973].

Habermas, J. (1981), Historia y crítica de la opinión pública, Barcelona, G. Gili [1962].

Habermas, J. (1988), Teoría de la acción comunicativa, Madrid, Taurus [1981].

Habermas, J. (1989), Conocimiento e interés, Madrid, Taurus [1968].

Habermas, J. (1992), La reconstrucción del materialismo histórico, Madrid, Taurus [1976].

Habermas, J. (1998), Facticidad y validez, Madrid, Trotta [1992].

Habermas, J. (2000), La lógica de las ciencias sociales, Madrid, Tecnos.

Habermas, J. (2000a), Perfiles filosófico-políticos, Madrid, Taurus [1971].

Habermas, J. (2000b), Aclaraciones a la ética del discurso, Madrid, Trotta [1991].

Habermas, J. (2002), Teoría y praxis, Madrid, Tecnos [1963].

Habermas, J. (2006), Entre naturalismo y religión, Barcelona, Paidós [2005]

Habermas, J. (2008), Conciencia moral y acción comunicativa, Madrid, Trotta [1983].

Habermas, J. (2009), Ciencia y técnica como ideología, Madrid, Tecnos [1968].

Habermas, J. (2010), El futuro de la naturaleza humana, ¿hacia una eugenesia liberal?, Barcelona, Paidós [2001].

Habermas, J. (2011), Verdad y justificación, Madrid, Trotta [1999].

Horkheimer, M. (2008), Teoría Crítica, Buenos Aires, Amorrortu [1968].

Horkheimer, M. (2010), Crítica de la razón instrumental, Madrid, Trotta [1947].

Kohlberg, L. (1971), «From Is to Ought», en: T. H. Mishel (ed.): Cognitive Development and Epistemology, New York, 1971, 151-236 [1971].

Kohlberg, L. (1992), Psicología del desarrollo moral, Bilbao, Desclée de Brouwer [1984]. Maestre, A. (1989), «¿El fracaso de la Teoría Crítica?», Daimon (Murcia), nº 1, pp. 225-236. Marcuse, H. (1968), Eros y Civilización. Barcelona, Seix Barral [1953].

Marcuse, H. (1968a), Cultura y Sociedad, Buenos Aires, Editorial Sur [1965]. 
Marcuse, H. (1971), «Industrialización y capitalismo en la obra de Max Weber», en: T. Parsons (ed.): Presencia de Max Weber, Buenos Aires, Ediciones Nueva Visión, 1971, pp. 123-144 [1964].

Marcuse, H. (1971). Razón y revolución. Madrid, Alianza.

Marcuse, H. (1976), Calas en nuestro tiempo, Barcelona, Icaria [1975].

Marcuse, H. (1985), El hombre unidimensional, Barcelona, Planeta [1964].

Marcuse, H. (2011). Entre hermenéutica y teoría crítica. Artículos 1929-1931. Barcelona, Herder.

Marcuse, H. y Romero Cuevas, J. M. (2010). H. Marcuse y los orígenes de la Teoría Crítica. México D. F., Plaza y Valdés.

Marx, K. (1980), Contribución a la crítica de la economía política, Mexico, Siglo XXI [1859]

Marx, K. (1980), El capital. Crítica de la economía política, Madrid, Siglo XXI [1867]

Marx, K. (1984), Manuscritos: Economía y Filosofía, Madrid, Alianza [1932]

McCarthy, Th. (1987), La Teoría Crítica de Jürgen Habermas, Madrid, Tecnos [1978]

McCarthy, Th. (1990) «Filosofía y Teoría Crítica en los Estado Unidos. Foucault y la Escuela de Fráncfort», Isegoría (Madrid), n 1, pp. 49-84.

Offe, C. (1969), «Técnica y unidimensionalidad. ¿Otra versión de la tesis de la tecnocracia?», en: J. Habermas (ed.): Respuestas a Herbert Marcuse, Barcelona, Anagrama, 1969, pp. 72-86.

Rawls, J. (2003), El liberalismo político, Barcelona, Crítica [1993].

Romero Cuevas, J. M. (2014), «La historicidad de la crítica. Un esbozo de la cuestión», Daimon (Murcia), no 61, pp. 93-111.

Ureña, E.M. (2008), La teoría crítica de la sociedad de Jürgen Habermas, Madrid, Tecnos [1978].

Wellmer, A. (1979), Teoría Crítica de la Sociedad y Positivismo, Barcelona, Ariel [1969].

Wellmer, A. (1990), «Comunicación y emancipación. Reflexiones sobre el "giro lingüístico" de la teoría crítica», Isegoría (Madrid), n 1, 1990, pp. 15-48. 